Hobson, P. N. \& ManN, S. O. (1957). J. gen. Microbiol. 16, 463-471

\title{
Some Studies on the Identification of Rumen Bacteria with Fluorescent Antibodies
}

\author{
BY P. N. HOBSON AND S. O. MANN
}

The Rorvett Research Institute, Bucksburn, Aberdeenshire

SUMMARY : Fluorescent antisera to a number of isolates of rumen bacteria have been prepared and used to demonstrate the presence of these organisms in situ in rumen contents. The serological tests for a specific organism in rumen contents of a number of calves agree with the isolations of this organism from the same sources. A microscope suitable for this work, the preparation and purification of antisera and the preparation of specimens is described.

Much work is being done at present on the biochemistry and bacteriology of the rumen contents of cattle and sheep. Two main methods of investigation are being used. One studies the reactions of whole, or almost whole, rumen contents transferred to suitable vessels in vitro, the other isolates organisms through the use of suitable media and then studies the reactions of these organisms in pure culture. In the latter case it is necessary to show that the organism which is being studied is one which is of importance in the rumen. There seems to be no general agreement among workers in this field about what is 'a true rumen organism'. Morphology alone is not conclusive as many rumen organisms have a similar appearance, and conversely, pleomorphism is common. In addition, an organism may not attack substances in vitro which it apparently attacks in vivo. This might be due to an unsuitable medium in vitro, or to the organisms being physiologically different, although having similar morphology. A method which shows the isolated organism near the foodstuff thought to be attacked would settle the problem. It would also be of interest to see whether similar organisms occurred in more than one animal or in different parts of the gut of the same animal without having to use isolation procedures. The presence of an organism in more than one animal may be an indication of its being a true rumen organism. These, and other considerations suggest that a method of identifying rumen organisms in situ would be of help. MacPherson \& Oxford (1952) described some work on the serological identification of rumen streptococci using the Neufeld 'Quellung' reaction, but this reaction is difficult to see in rumen contents and in any case is applicable only to organisms with a large capsule. However, antisera can be labelled by dyes visible in white or ultraviolet (u.v.) light in such a way as to provide a visual indication of their combination with a specific antigen. Fluorescent dyes have been applied to the localization of antigens in tissue sections (e.g. Coons, Snyder, Cheever \& Murray, 1950; Gitlin, Landing \& Whipple, 1953; Humphrey, 1955), and Coons \& Kaplan (1950) have described the preparation of fluorescein $i s o c y a n a t e$ and the coupling of this with serum proteins for such investigations. It was decided to try to apply this method to the identification in situ of 
rumen bacteria, as the method should distinguish any bacteria which react with the labelled antiserum and not only those which possess large capsules. A preliminary note on the method has been published (Hobson, Mackay \& Mann, 1955); further details are given below.

\section{METHODS}

Microscope. The microscope is shown diagrammatically in Fig. 1. It has been built up from parts of a number of microscopes, but most types could be adapted for use in similar work. A horizontal microscope was decided upon to allow the maximum intensity of $u . v$. radiation to enter the condenser and a monocular body gives a brighter image than binocular eyepieces. A powerful

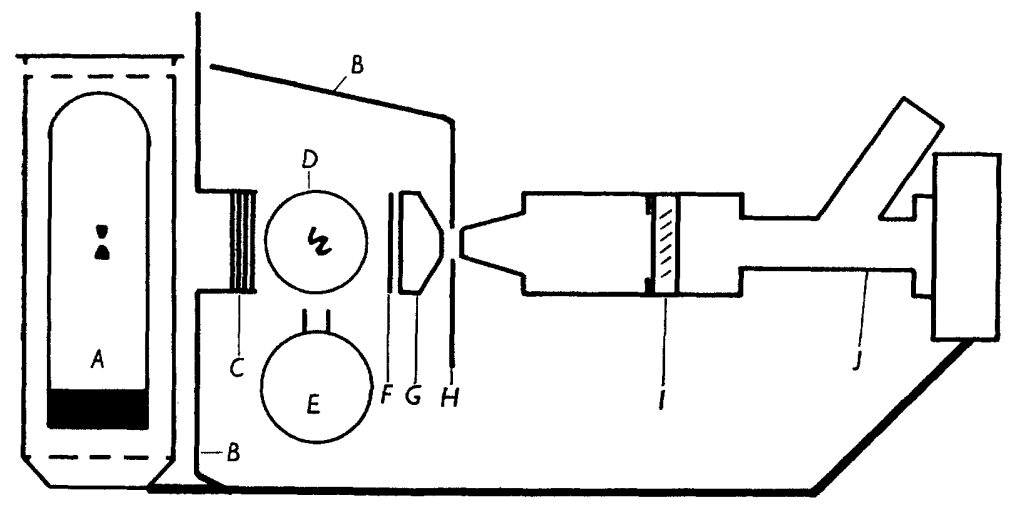

Fig. 1. $A$, High-pressure $\mathrm{Hg}$ arc with air cooling; $B$, screens; $C$, ultraviolet filter; $6 \mathrm{~mm}$. Chance OX 1 glass, $2 \mathrm{~mm}$. Wood's glass; $D$, source of white light; $E$, mirror to direct white light into microscope; $F$, phase annulus; $G$, quartz condenser; $H$, microscope stage; $I$, sodium nitrite solution filter; $J, 35 \mathrm{~mm}$. camera.

source of u.v. radiation is needed and for this a 250-watt high-pressure mercury arc (Type ME/D, British Thomson-Houston Ltd., Rugby) is used. The lamp is fitted in a centering metal-housing with an air blast for cooling. Glass filters are adequate for cutting out most of the visible light and transmitting the longer u.v. wavelengths (about 3650 A.) needed; the required thickness of filter was found by trial. A source of white light (in the following text white light is used to denote visible light used for examining objects, although blue or green filters were used as in ordinary microscopy) is placed at the side of the microscope and the mirror $E$ can be swung up to direct this light into the condenser. When most of the pictures shown here had been taken it was found possible to convert the microscope for phase-contrast by fixing a phase annulus to the glass disk $F$, which can be swung into the white light beam and then focused on the phase plate of an oil-immersion objective. The quartz condenser is not strictly necessary for this work; an ordinary two lens Abbe condenser is adequate if it does not itself fluoresce. Normal glass objectives are used, the most useful being a $\times \mathbf{9 0}$ achromatic objective fitted with an adjustable stop. To protect the eyes $5 \mathrm{~mm}$. of $10 \%(\mathrm{w} / \mathrm{v})$ sodium nitrite solution in an optical 
glass cell (made to fit on the tube diaphragm of the microscope by Tintometer Ltd., Salisbury, Wilts) is used. This sodium nitrite filter is preferred to glass filters as it does not change the colour of the fluorescent images, which is of great help in identifying some particles. The sodium nitrite solution is freshly made up and filtered when required; otherwise the cell is kept dry. A yellowish tinge develops on the glass after some months, but this can be removed with chromic + sulphuric acid. For routine observations a $\times 8$ or $\times 10$ eyepiece is used and for photography a $35 \mathrm{~mm}$. camera and viewing eyepiece (Beck Ltd., Mortimer Street, London, W. 1) is attached. The whole apparatus is mounted on a rigid framework which passes through the screen. 'Fluoroil' (E. Gurr Ltd., 42 Upper Richmond Road, London, S.W. 14) was generally used as immersion fluid. All lenses and filters should be free from finger marks or dust as these cause undesirable blue fluorescence in ultraviolet radiation. The filters used allow u.v. radiation and some blue and red light through, but the red is almost entirely focused out when the condenser is properly set for u.v. radiation (the condenser needs to be re-focused for white light). A cardioid condenser has also been used; this was not much improvement for u.v. radiation over ordinary illumination and was a disadvantage in identifying objects in white light. The best conditions for observing the fluorescence are with the oil-immersion objective stopped down to about N.A. 1. Observations are made in a dark room.

Photography. Since the viewing eyepiece transmits only a portion of the light which enters the camera it is sometimes difficult to see the images of fluorescent objects. Scanning is therefore done without the camera. If phase contrast is not used for white light the condenser diaphragm must be very much closed down to give any image at all and this accounts for the long exposures needed and the defects of the filters apparent in the photographs shown. Micro-file panchromatic film (Kodak Ltd., London) was used for all but one of the photographs shown. The exposures for fluorescence were 5-20 min. and for white light about 10 sec. Faster films did not give as good enlargements.

Organisms. The isolation of most of the organisms used for preparing antisera has already been described, or will be described (MacPherson, 1953; Mann, Masson \& Oxford, 1954; Mackay \& Oxford, 1954; Mann \& Oxford, 1954, 1955). All organisms were obtained from rumen or abomasum contents by the usual dilution techniques in suitable media.

Antisera were prepared in rabbits by the injection of washed formalin-killed or heat-killed suspensions of the organisms, over a course of some weeks. The titres were often quite low (streptococci $1 / 200$ to $1 / 1000$; lactobacilli $1 / 1000$ ) but some of the Gram-negative cocci and Gram-negative rod antisera gave higher titres $(1 / 10,000$ to $1 / 20,000)$.

Preparation of aminofluorescein. This followed the method of Coons \& Kaplan (1950) except that hydrogenation of the nitrofluorescein took about $9 \mathrm{hr}$. for each preparation and not $1 \frac{1}{2} \mathrm{hr}$. as these authors stated. Aminofluorescein I was generally used for conjugation.

Conjugation of antisera with fluorescein isocyanate. In general the procedure 
of Coons \& Kaplan (1950) was used, but the phosgene was obtained from a cylinder (I.C.I. Ltd., Widnes, Lancs) and the apparatus was thus under slight positive pressure. A column of liquid paraffin, coloured by a little Sudan III, acted as manometer and safety valve. The isocyanate solution was added slowly to the stirred serum solution at $1^{\circ}$ with an all-glass hypodermic syringe but even so, a small precipitate was formed. Some of this precipitate dissolved in the usual stirring-time of $20 \mathrm{hr}$., and continuation of stirring for $48 \mathrm{hr}$. did not lead to further dissolution. After dialysis the solutions were cleared by centrifugation at $20,000 \mathrm{~g}$ for $30 \mathrm{~min}$. at $0^{\circ}$. The buffered saline referred to later was the same solution as that used in the conjugation of the sera, but filtered through a $\mathbf{G} 5$ glass filter.

Fractionation of antisera. After conjugation a globulin fraction was obtained by precipitation of the serum + saline solution (25 ml.) with $18 \%(\mathrm{w} / \mathrm{v}) \mathrm{Na}_{2} \mathrm{SO}_{4}$ at room temperature (Humphrey \& MacFarlane, 1954). The precipitate was washed with $18 \%(\mathrm{w} / \mathrm{v}) \mathrm{Na}_{2} \mathrm{SO}_{4}$ and dissolved in sterile buffered saline (5 ml.). Paper electrophoresis showed that initially the serum contained two main protein components corresponding to the albumin and $\gamma$-globulin and both were fluorescent. The fractionated sera contained only one component, this was fluorescent and corresponded with the globulin of the original serum.

Preparation of protozoan powder. A suspension of rumen holotrich protozoa filled with starch granules was prepared by the method of Masson \& Oxford (1951), and the organisms dehydrated by washing in acetone and finally dried in vacuo over $\mathrm{P}_{2} \mathrm{O}_{5}$.

Preparation of mouse-liver powder. The livers of freshly killed mice were dissected out and chopped into physiological saline. After washing in saline the liver was ground to a fine powder in acetone and finally dried in vacuo over $\mathrm{P}_{2} \mathrm{O}_{5}$.

Absorption of antisera. ('Serum' in this and later paragraphs means the final solution of serum in buffered saline obtained after conjugation and dialysis as above.) For absorption by liver powder, protozoa or starch, the serum was shaken with the powder $(100 \mathrm{mg} . / \mathrm{ml}$.) at room temperature for $1 \mathrm{hr}$. and cleared by centrifugation. One absorption was usually sufficient. Absorption with bacteria was carried out by adding a thick suspension of the bacteria to the serum, shaking gently at room temperature for a few minutes and centrifuging. The reaction of the serum was tested under the microscope and when necessary the treatment was repeated.

Storage of antisera. The conjugated sera were stored at $2^{\circ}$ without additions. The whole unabsorbed conjugated sera have been kept for periods of up to two years, but after this time they seem to lose some of their specificity and give a poor fluorescence. After a few months storage, a slight cloudiness generally appeared in the sera, but this could be removed by centrifugation and it did not affect the reactions of the antisera. Occasionally a contaminant organism grew in samples of sera but, again, they could be cleared by centrifugation. Attempts to filter the sera were not successful.

Preparation of test slides. Thin $(0.8 \mathrm{~mm}$.) glass slides were initially used but better results were obtained using u.v. glass slides (Reicherts, Vienna). 
Ordinary coverslips were used. Samples of rumen contents were obtained either through permanent fistulae or by stomach tube, and of abomasum contents from the slaughter house. The samples were in most cases strained through gauze to remove the coarser particles. For rapid tests a sample of the rumen contents (1 loop) was mixed with buffered saline (1 loop) and antiserum (1 loop) on the slide, covered, blotted and examined immediately. Rather better results were obtained when the rumen contents $(1$ vol.) were mixed with buffered saline ( 2 vol.) and serum (0.5-1 vol.) in a tube and incubated at $35^{\circ}$ for $30 \mathrm{~min}$.; each volume need be only 0.1 or $0.2 \mathrm{ml}$. The buffered saline kept the $\mathrm{pH}$ value at about 7 (the optimum for fluorescein fluorescence), but with calf abomasum contents of initial $\mathrm{pH}$ value about 2 , a more concentrated buffer was needed. Drops were removed from the tubes for examination as wet films.

In general it was found that the following points must be noted in preparing slides. Loops, pipettes, etc., used in the antisera should not be warm, as hot apparatus coagulates some serum proteins and gives indefinite fluorescent masses on the slide. The films should be pressed as thin as possible to obviate background fluorescence from the layer of antiserum, but bubbles must be avoided or the slide will appear to have streaks and blobs of fluorescent material around the edges of, and in, the pressed-out bubbles.

\section{RESULTS}

Tests with different organisms showed that the antisera did not change their specificity on conjugation with aminofluorescein. With all the organisms tested one cell combining with the antiserum can easily be seen, but the degree of fluorescence varies amongst the organisms, the brightest being found, as expected, in the capsulated streptococci. Addition of non-conjugated homologous antiserum before adding conjugated antiserum prevents green fluorescence of the organisms. Incubation for $\mathbf{3 0} \mathrm{min}$. is sufficient to obtain maximum fluorescence. The organisms alone are generally black or faint blue in u.v. radiation with a suggestion that organisms grown in agar-containing media have a slightly increased blue fluorescence.

Naturally-occurring fluorescing materials in rumen contents are usually blue or white and occasionally red or yellowish, and objects which absorb conjugated antiserum fluoresce green. When the rumen contents are not initially strained through gauze or silk, the coarser particles of hay, etc., make the films thick and give a green fluorescent background, making it difficult to pick out fluorescing bacteria. In the initial tests with untreated unabsorbed conjugated antisera it was found that protozoal and foodstuff starches took up some serum. This non-specific reaction was not materially removed by absorption of the sera with dried protozoa or whole potato starch. This fluorescence could, however, be overcome by allowing the antisera to react with the rumen contents, then centrifuging the whole suspension at high speed and, after removing the supernatant fluid, washing the sediment with buffered saline. The sediment was then resuspended in buffered saline and films made as usual. This method had the disadvantage that all the foodstuff particles and organisms 
were compacted into one mass and no conclusions could be drawn as to the original positions of the organisms in relation to the foodstuffs; it was not generally used. Films of rumen contents fixed by heat or formalin appeared to absorb serum in a non-specific manner even after washing; again the original site of the organisms with relation to food particles, etc., was uncertain, so this method was not further investigated. Precipitation of a $\gamma$-globulin fraction decreased the non-specific reactions, but absorption of the antisera or globulins with liver powder gave the best results. The absorbed antisera seem to be quite specific in their reactions and normal rabbit serum conjugated with fluorescein and absorbed did not react with anything in rumen contents (P1. 1, figs. 1 and 2).

To enable a better picture to be obtained in white light attempts were made to stain the organisms in wet films with dyes as well as with conjugated antisera. Although a number of common bacterial stains were tried, in all cases it was found that sufficient stain to make the bacteria easily visible in white light masked or prevented the fluorescence of organisms treated with antiserum. The results of tests with a number of bacteria are given below. Specific organisms added to rumen contents could easily be picked out by using the conjugated antisera.

Amylolytic streptococci (related to Streptococcus bovis) have been isolated from sheep and calves, and serological tests have shown that many of these isolates are similar and are widely distributed. Plate 1, fig. 3 shows a pure culture of one strain of these organisms reacting with conjugated antiserum, and $\mathbf{P l}$. 1 , figs. 5 and 6, show a similar organism in a mass of material from sheep rumen contents reacting specifically with a conjugated antiserum. In these organisms the type specific antigen is in the capsule (Hobson \& MacPherson, 1954) and this fluoresces green, the cell body being darker.

Two different species of Gram-negative cocci have so far been isolated, one a facultative anaerobic coccus, Sarcina bakeri (Mann et al. 1954) from the sheep, and an anaerobic coccus, from the calf rumen, details of which are to be published (Mann \& Oxford). This calf-rumen coccus is probably related to the sheep-rumen coccus ' LC' described by Elsden et al. (1956). Both cocci vary in morphology and also in apparent reaction with antiserum. Some organisms appear to react only in a thin surface layer, the cell body being dark, with some the whole organism appears fluorescent and some $S$. bakeri organisms do not react. After absorption by liver powder the antisera to the two organisms did not cross-react, but some cross-reaction was found between two isolates of the anaerobic coccus, although the sera were specific at high dilutions. This crossreaction was removed by absorbing one antiserum with the other organism. Investigations so far have shown that the Gram-negative cocci fluctuate in numbers in any one sheep or calf. Plate 2, figs. 7 and 8, shows some of the $S$. bakeri in chain formation reacting with specific antiserum. In this case it will be noted that two of the organisms at the end of the chain had apparently not reacted with the antiserum. This phenomenon has been noted in pure cultures. Plate 2, figs. 9 and 10, shows one serological type of the anaerobic coccus reacting with antiserum in calf rumen contents. Experiments with six calves showed that where these organisms could easily be picked out in 
samples of rumen contents tested with conjugated antisera they could be cultured from the rumen contents in numbers equivalent to $c .10^{10} / \mathrm{ml}$. Where the organisms were not found by the serological tests they were either absent or isolated only at concentrations equivalent to $10^{2}$ or $10^{4} / \mathrm{ml}$. rumen contents. Further work is in progress on these organisms, but in both groups there seem to be a number of different serological types present in the rumen.

A number of species of lactobacilli, including Lactobacillus brevis, L. fermenti and $L$. acidophilus, were isolated from calves and conjugated antiserum to a mixture of antigens of some of these isolates was prepared. Plate 1, fig. 4, shows lactobacilli in mixed culture reacting with this antiserum and revealed by fluorescence under u.v. irradiation. Tests with rumen and abomasum contents from calves 7 and 24 days old receiving a milk diet showed the presence of lactobacilli which reacted with the antiserum, but many of these organisms were irregular in shape and somewhat granular. In one slide from the rumen contents of the first calf there seemed to be a definite cross-reaction of this antiserum with a group of small diplococci. Lactobacilli were not found in the rumen contents of calves or of a sheep fed on the normal adult animal diet. Many of the slides of gut contents of the younger animals were blurred by coagulated milk particles.

The isolation from the rumen of Gram-negative rods, mainly coliform types, has been described (Mackay \& Oxford, 1954) and conjugated antisera to these were prepared. The organisms are very pleomorphic, especially in older cultures, and the antiserum usually seems to react with a thin 'slime' layer around the organisms. A number of these organisms in sheep rumen contents which have reacted with conjugated antiserum are shown in $\mathrm{Pl}$. 2, figs. 11 and 12 . In one sample of sheep rumen contents two apparently diplococcoid organisms were seen to have reacted with the antiserum. Organisms which have reacted with this Gram-negative rod antiserum have not been found very often in the rumen contents tested.

\section{DISCUSSION}

The results given above were part of a preliminary survey of the possibilities of this method of identifying rumen organisms in situ. A selection of rumen organisms of differing morphology has been used and it has been possible to prepare conjugated antisera which can be shown visibly to have reacted with all these bacteria in pure culture. This reaction has shown the same, or serologically similar, organisms to be present in the gut contents of a number of animals. The method cannot be guaranteed to be entirely specific for one organism, but by suitable absorption of the antisera all gross non-specific fluorescence can be obviated and cross-reactions between different genera of bacteria seem to be rare. The reactions mentioned above were the only ones seen in the many slides examined. Some indeterminate masses of green fluorescent material are sometimes found in the rumen contents, but comparison with pure cultures kept under different conditions suggests that this fluorescent material is often disintegrating bacterial cells. Further work is now in progress to extend this method to different problems in rumen bacteriology. 
The authors would like to thank Miss M. Garvock for assistance in preparing sera and Miss $J$. M. Eadie for allowing us to take some calf rumen samples.

\section{REFERENCES}

Coons, A. H. \& KaPLAN, M. H. (1950). Improvements in a method for the detection of antigen by means of fluorescent antibody. J. exp. Med. 91, 1.

Coons, A. H., Snyder, J. C., Cheever, F. S. \& Murray, E. S. (1950). Localisation of antigens in tissue cells. IV. Antigens of rickettsiae and mumps virus. J. exp. Med. $91,31$.

Elsden, S. R., Volcani, B. E., Gilchrist, F. M. C. \& Lewis, D. (1956). Properties of a fatty acid forming organism isolated from the rumen of sheep. $J$. Bact. $72,681$.

Gitlin, D., Landing, B. H. \& Whipple, A. (1953). The localisation of homologous plasma proteins in the tissues of young human beings as demonstrated with fluorescent antibodies. J. exp. Med. 97, 163.

Hobson, P. N., Mackay, E. S. M. \& Mann, S. O. (1955). The use of fluorescent antibody in the identification of rumen bacteria in situ. Res. Corresp. 8, 30.

Hobson, P. N. \& MacPherson, M. J. (1954). Some serological and chemical studies on materials extracted from an amylolytic streptococcus from the rumen of sheep. Biochem. J. 57, 145.

Humphrey, J. H. (1955). The origin of blood platelets. Nature, Lond. 176, 38.

Humphrey, J. H. \& McFarlane, A. S. (1954). Rate of elimination of homologous globulins (including antibody) from the circulation. Biochem. J. 57, 186.

MACKAY, E. S. M. \& OXford, A. E. (1954). Some facultatively anaerobic Gramnegative rods from the rumen of the calf and sheep. J. gen. Microbiol. 11, 472.

MacPherson, M. J. (1953). Isolation and identification of amylolytic streptococci from the rumen of the sheep. J. Path. Bact. 66, 95.

MacPherson, M. J. \& Oxford, A. E. (1952). Use of the Neufeld capsular swelling reaction in identification of rumen streptococci in situ. J. gen. Microbiol. 7, ii.

Mann, S. O., Masson, F. M. \& Oxford, A. E. (1954). Facultative anaerobic bacteria from the sheep's rumen. J. gen. Microbiol. 10, 142.

ManN, S. O. \& Oxford, A. E. (1954). Studies of some presumptive lactobacilli isolated from the rumens of young calves. J. gen. Microbiol. 11, 83.

Mann, S. O. \& Oxford, A. E. (1955). Relationships between viable saccharolytic bacteria in the rumen and abomasum of the young calf and kid. J. gen. Microbiol. 12, 140.

Masson, F. M. \& Oxford, A. E. (1951). The action of the ciliates of the sheep's rumen upon various water-soluble carbohydrates, including polysaccharides. J. gen. Microbiol. 5, 664 .

\section{EXPLANATION OF PLATES}

Plate 1

Fig. 1. A burst protozoan, etc., in rumen contents of a sheep treated with fluorescent normal rabbit serum. The materials showing up fluoresced white and bluish. Ultraviolet irradiation; $\times 680$.

Fig. 2. The same field as in fig. 1 in white light. Phase contrast; $\times 680$.

Fig. 3. Pure culture of a rumen strain of Streptococcus bovis reacting with fluorescent antiserum. Ultraviolet irradiation; $\times \mathbf{7 8 4}$.

Fig. 4. Mixed culture of Lactobacillus spp. reacting with fluorescent antiserum. Ultraviolet irradiation; $\times 680$.

Fig. 5. Streptococci in rumen contents of a sheep reacting with fluorescent antiserum. Ultraviolet irradiation; $\times \mathbf{7 8 4}$.

Fig. 6. The same field as fig. 5 in white light; $\times 784$. 
Journal of General Microbiology, Vol. 16, No. 2

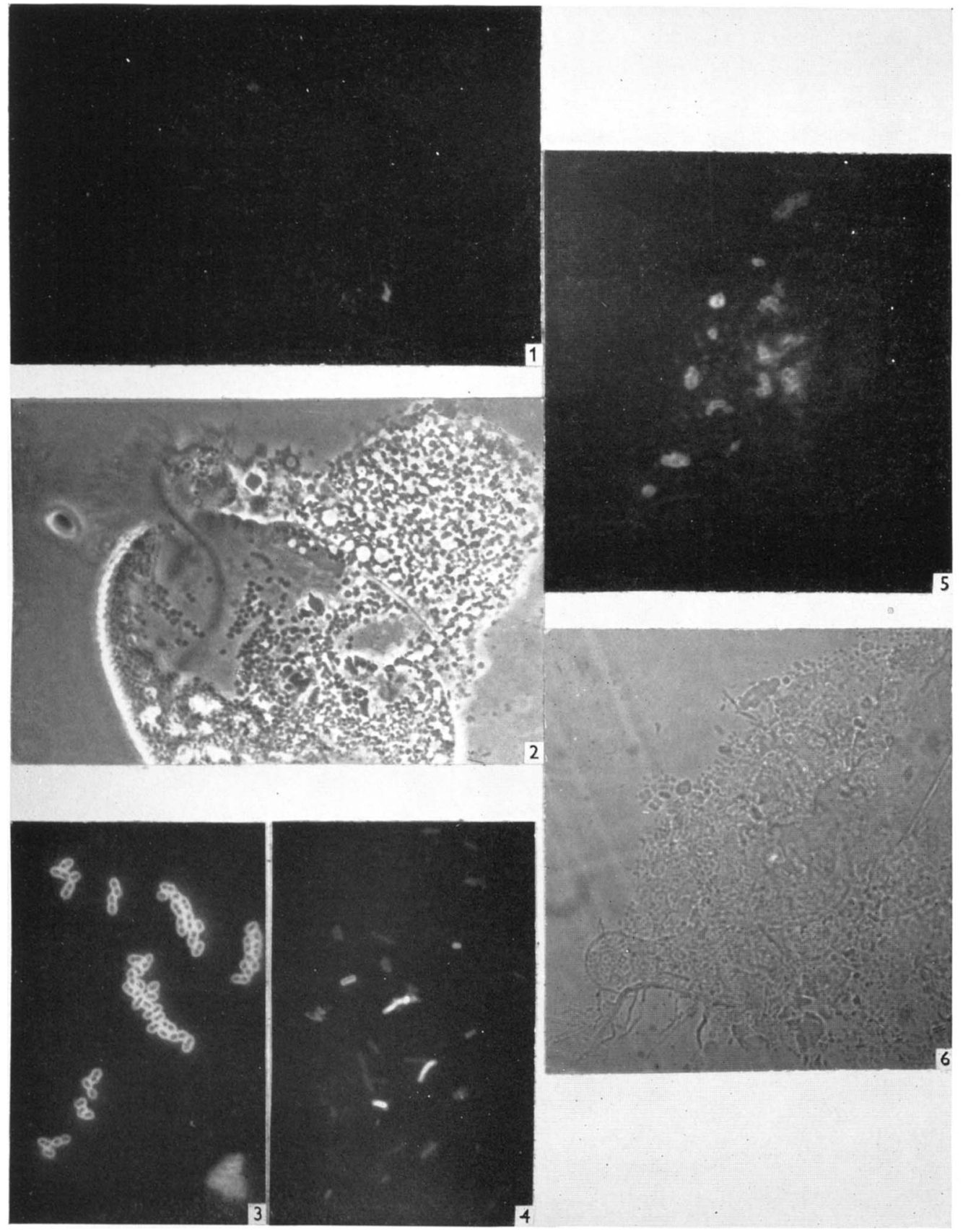

P. N. Hobson and S. O. Manx--inentification of memen bacteria. Plate 1

(Facing p. 470) 
Journal of General Microbiology, Vol. 16, No. 2
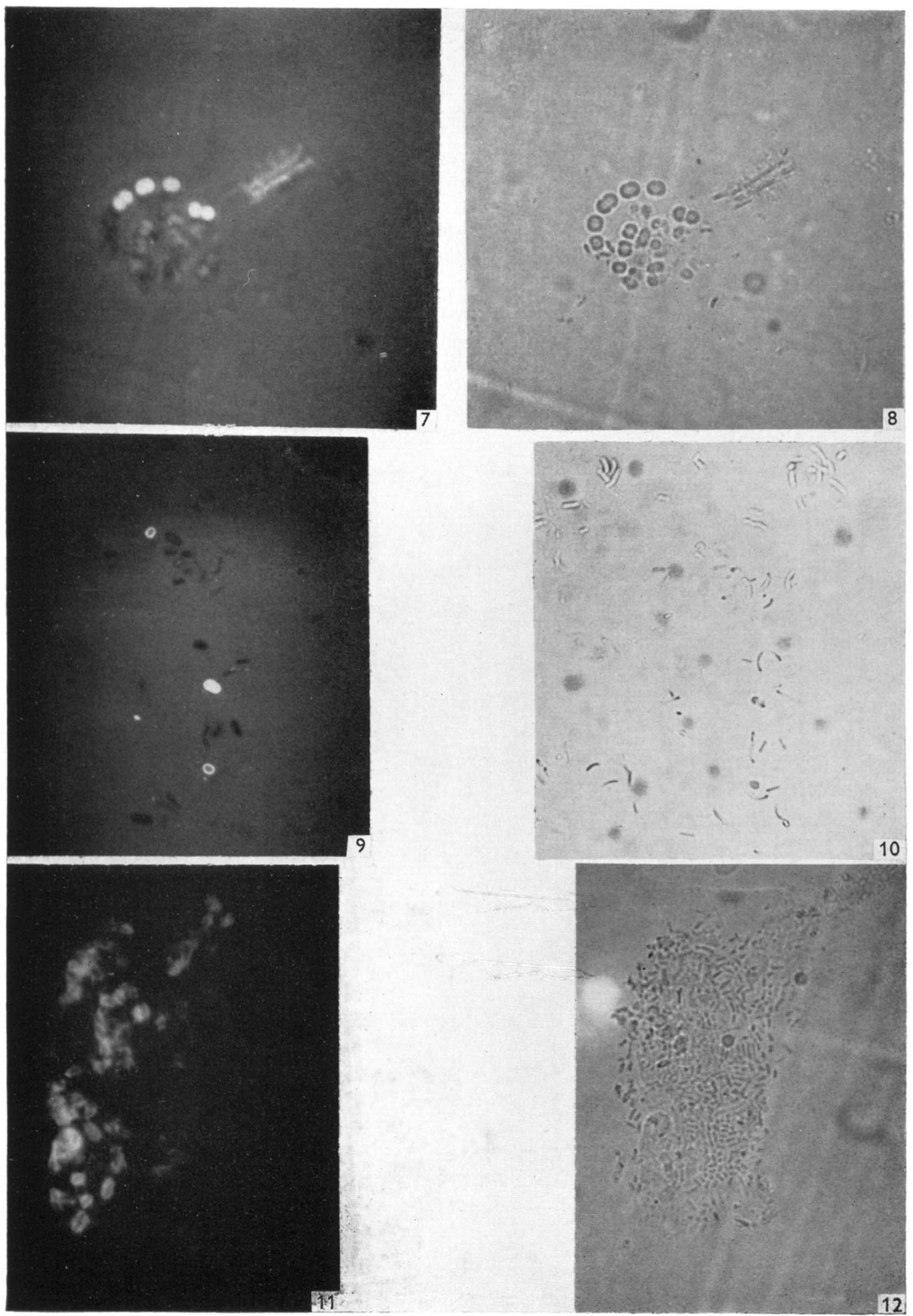

P. N. Hobson and S. O. Mann-Inentification of rumen baCteria. Puate 2 


\section{Plate 2}

Fig. 7. Facultative anaerobic Gram-negative coccus (Sarcina bakeri) in rumen contents of a sheep reacting with fluorescent antiserum. The piece of fibre in the field fluoresced blue. Ultraviolet irradiation; $\times 980$.

Fig. 8. The same field as fig. 7 in white light; $\times 980$.

Fig. 9. Anaerobic Gram-negative coccus in the rumen contents of a calf reacting with fluorescent antiserum. Ultraviolet irradiation; $\times 850$.

Fig. 10. The same field as in fig. 9 in white light. Some of the organisms in the field were motile and had moved between the two exposures. $\times 850$.

Fig. 11. Gram-negative rods in the rumen of a sheep reacting with fluorescent antiserum. Ultraviolet irradiation; $\times \mathbf{9 8 0}$.

Fig. 12. The same as fig. 11 in white light; $\times 980$.

(Received 24, October 1956) 